Revista Iberoamericana, Vol. LXVIII, Núm. 199, Abril-Junio 2002, 303-316

\title{
LA DICTADURA DE LOS CRÍTICOS \\ (POR UNA CRÍTICA IMPERFECTA... ALGUNOS AÑOS DESPUÉS)
}

\author{
POR \\ Juan Antonio García Borrero \\ Instituto Cubano de Arte e Industria Cinematográficos
}

\author{
La mayor necedad de los humanos, \\ homines mente capti, \\ es querer sacar conclusiones de todo. \\ La mayor parte de las preguntas \\ carecen de respuesta. Y son \\ infinitamente más las premisas \\ que las conclusiones.
}

Enrique José Varona.

En un viejo y mal encuadernado libro del filósofo cubano Enrique José Varona, encontré relatada la siguiente anécdota: a finales del siglo xix se dio a conocer una nueva escritora escocesa llamada Fiona Mac Leod. Los críticos saludaron con desmesurado entusiasmo la llegada de una artista que revolucionaba (según ellos) el canon e imponía presupuestos estéticos frescos. Por esa misma fecha, el consagrado William Sharp publicó una colección de poesías bajo el título de Lyra Céltica, en la que congregaba un grupo de poemas que hacían tangible su influencia en el imaginario poético de la nación; entre los versos escogidos sobresalían los de Fiona MacLeod, cuyas descripciones no obstante se atrevió a evaluar de “demasiado caleidoscópicas”. Tal gesto fue suficiente para que los mismos críticos que habían encumbrado a la poetisa desplegaran una furiosa ofensiva contra Sharp, calificando de mediocre su aspaviento y, por supuesto, enfatizando la superioridad de la obra de aquélla. Sharp no alegó nada: me parece advertirlo con su sonrisa desdeñosa, mientras en silencio seguía escribiendo a la par de su invicta rival y de aquellos críticos tan eruditos, enfrascados en demostrar el carácter singularísimo de la MacLeod. Todo se hizo muy embarazoso el día que William Sharp murió y el mundo se enteró de que éste y Fiona MacLeod eran la misma persona (Varona 254).

No pocas veces me he preguntado qué ventaja puede reportar a la humanidad que alguien utilice un par de cuartillas para intentar demostrar que lo que otro hizo está bien, mal o regular. Si la humanidad prescindiera de la crítica, ¿no vivirían más felices los hombres?, ¿no estaríamos acaso menos cercanos al resentimiento que todo señalamiento ajeno casi siempre nos reporta? Sin embargo, a estas alturas es ya bastante fácil demostrar que el hombre no puede vivir sin la crítica. El ser humano, en su brevísimo periplo vital, apenas tiene dos maneras de hacer tangible la existencia: a través de la creación y a través 
de la crítica de esa creación; allí donde hay creación, siempre le sucederá una fase crítica que aspira a convertir en algo superior eso que ya existe: incluso todo creador es un crítico en potencia, en tanto sus acciones están encaminadas a edificar una segunda naturaleza, a reemplazar con otra más armónica esta realidad que constantemente nos confunde, nos aturde. El creador es ese pequeño Dios que no sólo hará uso de la cuota de talento o sensibilidad que le ha correspondido para armar universos "seductores”; es también un crítico en tanto que de sus experimentos creadores puede deducirse una negación a lo existente o establecido. Luego, siempre se estará hablando del hombre como un animal esencialmente crítico: de allí su vocación a la porfía, o lo que es lo mismo, su voluntad insoslayable de cuestionarlo todo.

Hace algún tiempo necesité escribir sobre algunos de estos temas, y tantas interrogantes e incertidumbres desembocaron en un ensayo que entonces titulé Por una crítica imperfecta. Su recepción puedo asegurar sobrepasó las expectativas que como autor yo mismo me había planteado, ${ }^{1}$ pero en el grueso de los casos, siempre pude justificar el interés de los lectores a partir de la asociación casi mecánica que hacían estos con un texto fundacional dentro del pensamiento fílmico latinoamericano: "Por un cine imperfecto" (1969), escrito por Julio García Espinosa en las postrimerías de los años sesenta. Si bien conocía este texto y las reservas de su autor hacia la crítica de cine en sentido general, debo confesar que las principales ideas expuestas en Por una crítica imperfecta nunca fueron concebidas como un contrapunteo con la teoría defendida por el también realizador de Las Aventuras de Juan QuinQuin (1967) en tanto, en el fondo, podía intuirse una cierta coincidencia de reclamos.

Si se lee con atención, será fácil advertir que tanto el cine imperfecto como la crítica imperfecta parecen preguntar al final de todo una misma cosa: ¿qué tipo de crítica necesita un cine como el cubano (y en general latinoamericano) que está oponiendo a la dramaturgia ad usum otra manera de expresar (apresar) la realidad? Si el cine cubano está defendiendo una nueva moral fílmica, una moral cinematográfica que no es exactamente la que se sustenta con el esquema de valores que promueve la gran Academia, es indiscutible que sus postulados intelectuales habrán de ser por fuerza nuevos. De manera que, en el fondo, ambos textos intentaban promover el debate en torno a la necesidad de renovar nuestras estrategias reflexivas: García Espinosa decretando el deceso de la crítica como intermediaria entre el arte y los artistas, y el mío realizando una suerte de inventario donde se quería resaltar la decadencia (para no llamarlo franca ineficacia) de un método crítico rutinario, exento de riesgos interpretativos y sobresaltos poéticos. ${ }^{2}$

\footnotetext{
${ }^{1}$ Por una crítica imperfecta obtuvo el Premio Nacional de Crítica '95 que concede la UNEAC, así como el Premio Nacional de Ensayo de la Asociación Hermanos Saíz. Como texto fue publicado en forma de folleto en Argentina y apareció casi simultáneamente en la revista cubana Revolución y Cultura y en la colombiana Kinetoscopio.

${ }^{2}$ En Cuba, la situación del crítico es bien distinta al caso norteamericano o europeo donde se distingue entre los académicos que enseñan cine en las universidades, y los críticos que ejercen su criterio en los diversos medios de comunicación y que, desde luego, han de utilizar lenguajes diversos en aras de la comunicación. Por un lado, no abundan los libros teóricos dedicados a indagar en la esencia o naturaleza del cine, predominando las compilaciones de reseñas o las miradas historicistas; por el otro, tampoco es muy habitual que estos mismos críticos impartan clases en las
} 
Un examen genealógico del quehacer especulativo de la isla nos revelaría que hacia 1959, y no obstante su anémica capacidad de producción fílmica, Cuba contaba con una tradición crítica cinematográfica relevante. Nombres como los de José Manuel Valdés Rodríguez, Guillermo Cabrera Infante o Mirta Aguirre, entre otros, habían alcanzado una cierta notoriedad dentro de los más exigentes círculos intelectuales, a pesar del descrédito de nuestras gestiones productivas. Sin embargo, adivino el origen de las quejas de García Espinosa en el hecho de que los sesenta revolucionarios, tan fecundantes en el orden sociocultural (incluyendo la producción de filmes) no alcanzaran a conceder impacto similar a las estrategias de reflexión: la crítica de esa etapa, en el grueso de las ocasiones, siguió pensando “el cine” según los antiguos protocolos de interpretación, ésos en los que sobresalen por encima del análisis audiovisual el interés humanista en los aspectos morales.

En sentido general, nuestra crítica se fue haciendo cada vez más erudita, y el soporte literario (como es el caso de Cabrera Infante) llegó a alcanzar ribetes francamente hechizantes, pero si bien ha de hablarse de un crecimiento formal del ejercicio crítico, no puede decirse lo mismo de su capacidad para generar escepticismos, incertidumbres, dudas, que son a la larga los hechos que garantizan el crecimiento intelectual de todo gesto humano. En los años sesenta, la crítica oficial cubana siguió utilizando aquel instrumental de juicio tomado en préstamo de las tradiciones literarias y plásticas, y muy pocas veces su reflexión se dirigió al origen y naturaleza de ese lenguaje que utilizaba, creyendo natural la práctica de un enjuiciamiento que leía las películas como se lee cualquier novela, de allí que lo mejor del pensamiento en torno a las pretensiones del nuevo cine cubano se localice todavía en lo escrito por sus propios promotores (García Espinosa, Alfredo Guevara, Tomás Gutiérrez Alea, entre otros), y no por los críticos. El equívoco que aún sustenta la querencia analógica entre una lectura literaria y una lectura audiovisual tenía a su favor una circunstancia evidentemente sociocultural: desde los años sesenta o quizás antes, se hizo muy común que el ser humano llegara a la escuela con una relativamente amplia experiencia "fílmica"; antes de aprender a leer ya había aprendido a reconocer (Walt Disney y sucedáneos por medio) las peripecias y suerte de unos personajes muy parecidos a los que vemos en la realidad y reforzador a su vez de la estructura narrativa postulada por la novela decimonónica. Para colmo, la recepción literaria de este lenguaje se vería acentuada con la acción de maestros e intelectuales que siguieron viendo al cine tal como ellos apreciaban a la literatura.

Se ha dicho que la crítica cinematográfica decidió su actual suerte académica precisamente allá por los años sesenta, cuando su irrupción en los planes de estudio de las universidades y otros centros de educación superior dictaminó su moderno campo de expectativas. La crítica rápidamente alcanzó el rango de una actividad similar a la investigación literaria y la antigua aproximación periodística fue reemplazada por una labor interpretativa donde comenzaron a abundar los textos llenos de citas culteranas,

universidades o en la Escuela Internacional de Cine y Televisión de San Antonio de los Baños, por poner sólo un ejemplo de instituciones que, en teoría, debieran explotar los conocimientos de éstos. En este sentido, no creo que exista en Cuba una clara distinción entre "académicos” y "críticos periodísticos”. 
alusiones a complejísimos métodos de investigación, extensísimas notas al pie de página que a veces duplicaban el tamaño de la idea central; con esto, fue conformándose toda una casta de entendidos que, en nombre de una "autoridad" que Weber calificaría de carismática, y llevando hasta las últimas consecuencias la devoción por la elaboración exquisita de significados fílmicos, terminaron conformando la actual aristocracia del saber cinematográfico, y de paso, el establecimiento de lo que pudiéramos llamar "la dictadura de los críticos”.

Lo raro es que esta dictadura se sigue asumiendo sin que ninguna de las partes implicadas tenga mucha conciencia de ello. Pocas veces los críticos se preguntan de dónde les ha llegado esa innegable autoridad intelectual que han heredado y que a diario ejercen en periódicos, programas de radio y televisión o eventos altamente especializados. Asumen su facultad de dictar cánones artísticos e imponer la obediencia estética, con la misma naturalidad con que un fanático religioso cree portar en exclusiva, la buena nueva de la salvación del mundo: de seguro tal arrogancia encontró su origen cuando, ante la autoridad telegénica del crítico de cine, hace ya algún tiempo sucumbían por igual lo mismo un médico que un obrero, un abogado que un ama de casa. Aquel espectador (no importaba el grado de instrucción) sentía verdadera fascinación con las acrobacias retóricas del especialista: podía discrepar o no con el punto de vista esgrimido por éste, pero ante todo prevalecía la creencia (tal vez falsa) de que se estaba efectuando un verdadero debate entre entendidos y neófitos, privilegio intelectual nada común en la historia de la civilización.

El crítico de entonces, por su parte, se estaba entregando a una tarea de iniciación colectiva de su credo y para ello no temía en descender del podio de sus excelsas ideas al mismísimo fondo de la vida, en busca de todo tipo de adeptos. Sin embargo, lo que en un comienzo fue indiscutible liderazgo carismático, con el tiempo devino simple autoridad tradicional que, como bien se sabe, se apoya en el principio de la costumbre. Hoy buena parte de la crítica que se ejerce en Cuba descansa sobre un fundamento intelectivo consuetudinario, de allí que predomine el sentimiento conservador antes que el revolucionario: los críticos prefieren operar con las tácticas y estrategias heredadas del pasado o de sus maestros, sin cuestionar la confiabilidad o vigencia de aquello que manipulan o someter a fiscalización los principios antiguos que sostienen cada una de las argumentaciones. Esta tendencia a respetar la costumbre no significa que la crítica como grupo no se nutra de conflictos internos que ayudan a mantener su vitalidad, pues si bien hay un sector que sigue atado a los viejos modelos de interpretación explícita, hay otro que ha optado por novedosos modos de lectura, como la sintomática, ésa que supone el rastreo de significados ocultos a los propios realizadores; sin embargo, tales enfrentamientos se siguen concibiendo en un terreno ya por el momento vedado al espectador promedio, por lo que, más que una revolución, la maniobra recuerda a esas clásicas revueltas estudiantiles que piden abundantes reformas, pero confiando en el mismo sistema (la misma dictadura) de siempre.

Es irrefutable que la consolidación de los críticos de cine como una "élite cultural" ha sido vertiginosa y contundente. A los ojos del ciudadano medio, un crítico de cine siempre ha tenido mucho más “prestigio” que su homólogo de las artes plásticas, el ballet o la literatura; sin embargo, ese reconocimiento últimamente ha sufrido variaciones, y yo 
diría hasta decepciones, en tanto el diseño de armónicos sistemas interpretativos, aun cuando en apariencia pudieran estar protagonizándose edificantes desencuentros, muy pronto reveló el lado oscuro del asunto: mientras que la vida seguía su rumbo a veces caótico y casi siempre impredecible, mientras el espectador aturdido asistía a sucesivas renovaciones audiovisuales empeñadas en envejecer hoy de manera radical lo que hasta ayer era rotunda novedad, mientras se abarrotaban de innumerables estímulos virtuales (tan reales como los de siempre, o quizás más) el espacio perceptivo del hombre, la crítica de cine se esforzó por crear la sensación de una mirada dirigida hacia el reino de lo intocable, lo cual pudo lograr de dos maneras: a) deshaciéndose de todo aquello que pudiera resultar contaminante por efímero e inestable, y que por lo general se asocia al gusto pésimo y caprichoso de las masas; b) enfatizando el uso de una terminología sólo apta para iniciados.

No creo que sea difícil entender desde esta perspectiva por qué el actual espectador ha dejado de prestarle la atención de antes a la crítica de cine. No es que le haya retirado la autoridad que desde un inicio le concediera (de hecho, hoy hay más críticos que nunca), pero la rutinización de métodos de lectura por un lado, y la esoterización por el otro, ha terminado por configurar una nueva situación en la que la crítica parece cada vez más y más alejada del público y de lo que ha de resultar su deber más sagrado: la ilustración práctica de aquellos espectadores a quienes teóricamente se dirige. En la actualidad, y a pesar de la aparente democratización de la emisión y recepción fílmica, la mencionada dictadura de los críticos no muestra indicios de reblandecerse; todo lo contrario, pues si bien cada vez se escribe una mayor cantidad de libros sobre cine, aparecen nuevas revistas especializadas, se discuten ambiciosas tesis universitarias, se organizan coloquios internacionales y se otorgan premios económicos bien tentadores, cada vez son menos los que participan de estas discusiones. Así, en nombre de un supuesto interés público (que en realidad es un interés grupal y hasta individual) este pequeño grupo de entendidos dicta los cánones que en adelante la gran mayoría asumirá como “intocables”, aunque a la larga (como todo aquello que se escucha pero no se entiende) no los tendrá en cuenta y mucho menos aplicará en la vida; he allí la gran tragedia de esa crítica cada vez más despótica: su “perfección” provoca el radical distanciamiento de aquellos espectadores (los más) que nunca se atreverán a someter a debate lo establecido por "la autoridad crítica" ni reconocerán las supuestas angustias de ésta como sus propias angustias, quedando la sensación de una crítica deshumanizada.

Por otro lado, es demasiado elocuente que, mientras de manera eventual en las pantallas se pongan de manifiesto rupturas cinematográficas, sobresaltos fílmicos que la propia crítica se encarga de etiquetar como modernos o posmodernos, ella misma no sea capaz de proveerse de esas saludables automutaciones: si se revisan bien el grueso de los procedimientos reflexivos de los últimos veinte o treinta años, se verá que éstos descansan sobre las mismas formalidades utilizadas con el nacimiento del impresionismo crítico. Esta inmutabilidad, desde luego, no significa que todos los especialistas escriban lo mismo; a lo que me refiero es al hecho de que todavía buena parte de la crítica moderna se complace en reiterar el esquema retórico con que se comenzó a pensar "en serio" el cine: si bien esta crítica gusta de alabar las experimentaciones cinematográficas que a ratos aparecen en las pantallas, llámese neorrealismo italiano o Dogma’95, esos descubrimientos 
suelen resaltarlos según el viejo entusiasmo adjetivista a través del cual se siguen utilizando las mismas categorías estéticas de siempre.

Como consecuencia de ello, los grandes problemas epistemológicos, relacionados con la precisión del saber, la confiabilidad de las fuentes de nuestro conocimiento fílmico, así como el vínculo entre aquello que se comenta y "la cosa fílmica en sí” comentada, nunca resultaron del interés de los críticos. Entre los cubanos, Julio García Espinosa fue uno de los primeros en percatarse de la necesidad de renovar esos métodos reflexivos, y en tal sentido, "Por un cine imperfecto" perdura como uno de los textos más proféticos escritos en Cuba al respecto. A mí me sigue pareciendo el ensayo más provocador con que ha contado el pensamiento fílmico de la isla, sobre todo porque muchas de sus ideas, lejos de ser superadas por el logos insular, se confirman en sus predicciones y alertas, al tiempo que sus líneas nos revelan a un pensador que más que embriagarse con la posibilidad de convertir al cine en "el arte de nuestro siglo," se sabe protagonista de una nueva edad cultural: la audiovisual, con todas las ventajas e inconvenientes que ello implica.

Si el ensayo es todavía importante, no se debe a que contenga tesis irrefutables; todo lo contrario, es valioso porque alimenta ideas encontradas, novedosas. De hecho, ha sido el propio García Espinosa el que mejor se ha referido a los aciertos y limitaciones de un texto escrito en una década en la que “provocar” parecía el gesto más legítimo:

En realidad todo ese artículo lo hago consciente de que estoy provocando, como pudiera funcionar una acción plástica en la actualidad. No se está diciendo la verdad absoluta, se está provocando. Ahora diría que el papel del crítico como intermediario es el que cuestiono un poco. Si el crítico parte de la base de que hay un público que no entiende suficientemente y que entonces él le va a facilitar el conocimiento de esa obra, hay como una actitud paternalista con ese público. Prefiero una crítica que no se plantee esos términos. (...)

La crítica no sólo puede ser una forma de arte sino una forma de desalienación, que es lo más importante de todo, la desalienación. Que la gente vea el arte no como un objeto pasivo sino que pueda mantener su espíritu crítico y su independencia frente a esa obra. (Ríos 23)

Hay que señalar que las distancias de García Espinosa hacia esa crítica arrogante y paternalista, que se cree dueña de una verdad absoluta transmitida a unos pocos elegidos, ya habían sido expuestas en uno de los más tempranos artículos del ensayista. Su texto "La crítica y el público” anunciaba no pocas de las inquietudes que más tarde formarán parte del contenido de "Por un cine imperfecto", como cuando afirma que "es un poco pedante concebir al crítico como una especie de traductor de la obra de arte” (13), y sugiere el enriquecimiento de las estrategias reflexivas con la incorporación del debate, las charlas, el intercambio activo con el público, de manera tal que pueda establecerse una verdadera relación entre la crítica y el espectador, según lo que la "nueva realidad” estaba demandando. Por los días que escribo estas líneas García Espinosa acaba de manifestar:

Quisiera que quedara claro de una vez que no me siento pontífice de nada. Tengo angustias, sólo angustias, y cuando siento que puedo compartirlas con alguien, (como me sucede con los actuales jóvenes de la crítica) me estimula y me enriquece. He dicho, en 
una ocasión, en medio de las utopías de los sesenta, que podíamos llegar a prescindir de los servicios de la crítica, como de los servicios de los cineastas, como que el arte no iba a desaparecer en la nada, que el arte desaparecería en el todo. Para algunos estas posiciones han sido siempre caldo de cultivo del populismo. A pesar de haber enfatizado yo mi rechazo al populismo, de haber manifestado, en más de una ocasión, que es el cine de Hollywood el ejemplo más refinado y tecnificado del populismo. Pero para muchos amantes de las Bellas Artes el arte es el arte de las minorías y basta. Los demás deben dedicarse a superarse para alcanzarlo. Es parte de la verdad, pero sólo parte. El arte de minoría lo asumimos todos y muy legítimamente, como parte de nuestro acervo, de nuestro patrimonio cultural. Pero los amantes de las Bellas Artes se equivocan cuando piensan que ante esta herencia no hay otra alternativa, que fuera de ésta solo se alza el populismo y la mediocridad. Es una especie de terrorismo intelectual. Esta "culta” herencia ha sido llevada al cine. Y son estos criterios los que suelen aplicarse para medir la jerarquía estética de una película. Pienso que sería de gran beneficio para el arte, y para el cine en particular, ampliar estos conceptos, asumir que pueden coexistir otras alternativas. La crítica más reciente camina en esa dirección. Es muy estimulante (García Borrero, “Las estrategias”).

Ahora, ¿qué puede estar pasando en la crítica cubana actual que despierta el entusiasmo de García Espinosa? ¿Hay en verdad indicios de renovación o desalienación en el análisis cinematográfico nacional?; ¿puede hablarse de una crítica que se preocupa por dejar a un lado la mera contemplación para convertirse ella misma en creación estética, participativa y, sobre todo, eficiente ante su público moderno? En un trabajo discutido en las sesiones teóricas del Noveno Taller Nacional de Crítica Cinematográfica (Camagüey 2000), el estudioso Frank Padrón Nodarse nos hizo notar la existencia en la Cuba actual de un estilo (¿o método?) de análisis fílmico, que prescinde del lenguaje más tópico (¿más clásico?), aquel que (a la manera de un adolescente que cuenta sus impresiones a un compañero) describe lo que ha visto, pero no lo que ha observado, es decir, que habla de las superficies pero no de las texturas que conforman esas superficies. A esto, si no interpreto mal, lo nombra post-crítica. Para Padrón, "la post-crítica, hija legítima de la postmodernidad, es un modo de dignificar la condición del crítico, de subrayar aún más su esencia de escritor, su artisticidad, su misión heurística y de elevar la estatura de lo que escribe a aquello sobre lo que escribe, patentizar que su texto es tan hermoso, profundo y complejo (o al menos puede serlo) que el del (otro) escritor, cineasta, pintor o artista cualquiera sobre el cual centra su punto de mira.”

El trabajo de Frank Padrón me hizo recordar de inmediato las discusiones del Taller anterior, cuando una buena parte de los implicados se enfrascaron en un agudo debate en torno al lenguaje que debía utilizar el estudioso. No es la primera vez que se habla del asunto, pero sí es, me parece, la primera ocasión en que se ha intentado conceptualizar los rasgos de esta nueva manera de escribir sobre el cine que se viene practicando en el país y que, no sin cierto dejo peyorativo, algunos califican de postmodernizante. Lo del post no me molesta siempre que signifique un artificio a través del cual podamos precisar cronológicamente cuándo comenzó a ser más sistemática esta forma de escribir, pero de allí a que encierre una expresión de novedad (entendida ésta como la pueril idea de creer que se está inventando algo) ya hay un largo trecho. 
El texto resulta revelador de un nuevo estado de ánimo en la crítica cubana, pero donde no me deja conforme es en la, a mi juicio, desmedida subjetivización del fenómeno. Quiero decir, el hecho de que el ensayista apenas repare en tres o cuatro críticos como los posibles signos de “la nueva percepción,” me parece cuando menos reductor, pues estamos hablando de un sentir que es mucho más plural de lo que se cree. La misma comunidad de intereses que Padrón Nodarse advierte en el reducido grupo que nombra, la percibo en un conjunto de trabajos hasta ahora aislados, pero que si lográramos agruparlos revelarían detrás de la diversidad, afinidades en el estilo y también en lo conceptual; es decir, que más que un análisis individualista, preferiría un enfoque de conjunto, que permitiera captar “el espíritu,” “el ambiente” a que hace referencia García Espinosa.

Por otro lado, tampoco me queda claro si para Frank Padrón esa reciente postura ante el lenguaje es lo que está determinando el hipotético crecimiento de nuestros análisis, y aquí tendríamos un nuevo punto de contacto (o de fricción) con la teoría manejada por García Espinosa en torno a la necesidad de un lenguaje que priorice la reflexión audiovisual antes que la literaria, al afirmar que "debemos llegar a liquidar esa pelea desigual de un lenguaje literario que pretende hacer el análisis crítico de un lenguaje audiovisual. Nada impide que una película pueda ser el análisis crítico de otra película” (Una imagen 54). ¿Ha logrado ser la crítica cubana menos literaria y más audiovisual? Es evidente que no y ello se supone sea uno de sus problemas más urgentes a resolver; ahora, aun cuando el enfoque crítico deba prestar más atención a la naturaleza íntima del cine, quedaría siempre pendiente también como problema la calidad poética del lenguaje que se utilice para expresar esa “audiovisualidad”: ¿cómo ha de escribir un crítico de cine?, ¿como un escritor que escribe sobre cine (Cabrera Infante) o como un científico especializado en términos culturológicos, técnicos y, por tanto, indiferente a cualquier alarma poética?

Es verdad que los síntomas más claros del crecimiento de la crítica cinematográfica cubana en la actualidad parecen revelarse con el énfasis literario de sus últimas propuestas, mas tampoco creo que se trate sólo de un problema de lenguaje, pues al igual que a Borges, la certidumbre de que todo está escrito también a mí me anula y hasta "afantasma”: más bien creo que es el ánimo de integrar a las tradicionales maneras de enfocar al cine estrategias reflexivas importadas de otros campos (como la filosofía, por ejemplo) lo que va marcando la diferencia. Es real que la simple mención de un filósofo u otro no garantiza que se domine el aparato de pensamiento que aquellos despliegan, pero a todas luces esta preocupación cada vez más creciente por rebasar el lenguaje estrictamente cinéfilo, nos va beneficiando en este deseo de renovar la tradición; se ha comprendido que hablar del cine desde un punto de vista filosófico tiene una indiscutible ventaja: desde la filosofía se puede hablar del cine y de sus efectos en la vida; desde el cine se puede hablar sólo del cine. Ya sé que esta aproximación filosófica todavía no es todo lo sistemático que debiera ser, pero es mucho más que la estrechísima mirada de antaño, cuando citando a Marx sin haberlo leído, se solía afirmar cualquier cosa y nadie lo discutía.

Lo cierto es que hoy una zona de "la nueva crítica cubana” parece hastiada del lenguaje tradicional de interpretación fílmica, y hasta pareciera todo un milagro que tanta diversidad de lenguajes y estrategias no suponga ya una nueva Babel; por el contrario, tal vez está siendo la mejor prueba de lo legítimo a aspirar a una pluralidad de enfoques en 
nuestra analítica, donde (eso sí) el denominador común lo sea exclusivamente el rigor expositivo. Este rigor puede alcanzarse a través del manejo de complicadas categorías culturológicas, pero también mediante el uso de un lenguaje afincado en la más castiza tradición, en tanto lo que vale es la idea, no la palabra, y aquí nos aproximamos a algo que resulta esencial: el deber, el imperativo de que cada palabra utilizada denote el significado de aquel concepto que se quiere esclarecer. De nada vale utilizar el más elaborado de los lenguajes si al final no queda como saldo un aporte intelectual que revele nuevas facetas del problema que se examina; un texto que sólo atienda a la belleza o claridad de sus términos sin procurar el establecimiento de nuevos conocimientos está definitivamente más cercano a la (mala) poesía que a la crítica, y de lo que se trata es de convertir al razonamiento en otra forma de presentir la poesía que ya existe en el objeto, sin olvidar la gestión más importante: la heurística, o para decirlo en términos bien caros a Sócrates, la mayéutica.

Creo entender a García Espinosa cuando se pone en guardia ante aquellas exquisiteces literarias que comentan el cine; en verdad, el lenguaje nunca pasará de ser un medio encaminado a lograr un fin: el posible esclarecimiento de un por qué estético. Pero cuando el lenguaje se convierte en fin, cuando el crítico termina embriagado con la belleza que descubre en la combinación de estas u otras palabras, cual si se tratara de un impostergable poema dictado desde el más allá, cuando la fabricación indiscriminada de significados fílmicos reemplaza a la investigación de los que ya existen en el objeto de nuestra percepción, cuando la razón se convierte en sierva de la emoción, el crítico termina creyéndose más importante no ya que aquello que critica, sino que la propia crítica que ha hecho. En adelante, el estilo literario pondrá en los primeros planos al autor que, humano al fin, no hará más que reiterar una y otra vez sus obsesiones estilísticas: en esos casos, siempre resultará más fácil reconocer el (meta)lenguaje del crítico que lo que en el fondo éste quiere expresar.

Y si bien la otra crítica, la crítica "sin personalidad," se condena ella misma al reino de lo efímero, también sabemos que el ejercicio de la palabra por la palabra es pura veleidad. Fue Leibniz el que inventó el término psitacismo para referirse a esas descontroladas ansias de hablar por hablar, sin concederles a las expresiones que se profieren el sentido más racional. "Razonamos con frecuencia con palabras, sin tener presentes en la mente los objetos que aquéllas representan,” decía el filósofo mientras hacía derivar del término griego psittakós (lorito, papagayo) la teoría de que es preciso buscar la verdad no en los vocablos sino en las ideas universales que estos significan, so pena de, incumpliendo con ello, convertir el lenguaje en un sucedáneo del que ostenta el papagayo. En no pocas ocasiones, la crítica cubana se ha mostrado cautiva de toda una psitacosis intelectual, muy similar a esa penosa enfermedad que los loros transmiten al hombre, pero donde en vez de afectarse las vías respiratorias, lo que se pone en riesgo es el intelecto y el sistema lingüístico: en esos casos, el crítico habla y habla y habla, o escribe y escribe y escribe, sin importarle que entre la palabra y el objeto que ella evoca exista una correspondencia así sea mínima.

Dicho psitacismo crítico no está determinado por la utilización más o menos frecuente de términos considerados gongorísticos o claros, sino en la capacidad o incapacidad de revelar al lector la íntima relación de esas palabras con el significado que 
se pretende demostrar. Desde que en la segunda mitad del siglo XIx, Mallarmé convirtiera la célebre frase de Fenelón ("no se escribe más que para ser comprendido”) en centro obsesivo de sus ataques y derogaciones, las querellas sobre la función del lenguaje en su sentido estético pasaron a ocupar nuevas dimensiones, y de alguna manera la polémica en torno al culteranismo y el conceptismo conoció de una reedición. Boileau, quien se ha dicho transformó en poesía la filosofía de Descartes, había terminado por canonizar con sus preceptos el llamado "buen gusto": con ello legaba a la humanidad el orgullo por la lengua más castiza, hasta el extremo de ser llamado de manera indistinta "el poeta de la razón” y “el legislador del Parnaso"; sin embargo, tanto purismo formal dispuso un lastre casi infinito a la espontaneidad y a la pasión que debe acompañar a todo artista, y aquí incluyo desde luego al crítico.

Esa falta de pasión, de imaginación, de riesgo creativo, puede resultar a la larga un motivo de incomunicación similar a lo gratuitamente ilegible. En la escritura crítica cubana, me he encontrado textos que, en su afán de máxima legibilidad, no han hecho más que computar las ideas que con seguridad el lector ya estaba esperando leer y, que por ende, han despreciado la oportunidad de imponerle una meta de crecimiento, un desafío intelectual a su destinatario, una aventura: son esos textos que le dejan a uno la pésima certeza de haber leído un mensaje escrito en la arena; por el contrario, he consultado otros donde la supuesta dificultad de su tema se convierte en un imperativo para alcanzar un nuevo nivel en el acceso al conocimiento: hablo de ese tipo de texto que nos obliga o estimula a pensar más, así sea para rebatir con determinada intensidad lo que el autor nos propone, reafirmando en el crítico aquel carácter que Descartes se enorgullecía en declarar de sí mismo: "Yo soy una cosa que piensa, es decir, que duda, que afirma, que niega, que conoce algo de las cosas, que ignora mucho más, que ama, que odia, que quiere, que no quiere, que también imagina y que siente". ${ }^{3}$

De acuerdo, a mí también me parece de mal gusto el uso y abuso gratuito de términos culteranos que sólo sirven de cosmético temporal al ego crítico, y para colmo, convierten en verdaderos criptogramas el enunciado, pero mucho menos aprecio ese otro extremo que se conforma con la tautología complaciente, la adolescencia literaria y el premeditado desconocimiento de los métodos científicos de investigación: términos como epistemología, apolíneo, dionisíaco, axiológico, óntico o teleología, por mencionar solo algunos, nos podrán causar fobia, repugnancia, indiferencia y hasta parecernos ajenos al cine, pero ello no quita un ápice de su eficacia instrumental, validada por el tiempo y por los hombres más sabios que ha conocido la humanidad: ¿cuál puede ser el inconveniente en que nuestra crítica, además de erudita en su terreno, se pretenda sabia?

\footnotetext{
${ }^{3}$ En el caso de la actual crítica cubana, y a pesar de no estar muchas veces de acuerdo con sus puntos de vista, éste podría ser uno de los rasgos más valiosos que les encuentro a las escrituras de Rufo Caballero, Dean Luis Reyes, Frank Padrón Nodarse o Jorge Luis Urra, quienes no sólo me comprometen a salir de esa pasarela de lugares comunes en que puede convertirse una crítica de cine cuando reitera con pasmosa uniformidad los valores de la fotografía, la música, el guión de una película de Hollywood, sino que además me imponen el reto de la investigación, del ascenso racional. Y con esto no quiero decir que ahora todo el mundo tenga que escribir como ellos: sólo saludo la común vocación de convertir sus prosas en problemas y no en falsas soluciones.
} 
Lograr dominar esos términos y “naturalizarlos” en nuestros predios fílmicos, no para hacer ostentación vanidosa de ellos, sino para traducirlos a un lector, a un espectador no iniciado (aunque no por ello menos inteligente), es tal vez la gran misión del crítico, pues en realidad, excepto los neologismos infundados y narcisistas, no existen palabras oscuras o indescifrables siempre que éstas formen parte de ese tesoro común que es la cultura universal; no existen palabras ilegibles, sino escritores incapaces de develar el significado último de sus pensamientos y/o lectores sedentarios o impacientes que no desean aprender más de lo que hasta ese instante creen que saben. Pretender que el lenguaje sea siempre “transparente y fácil” es lo mismo que aspirar a que nuestros hijos se expresen todo el tiempo como lo hacían hasta la edad de seis o siete años. Es decir, claridad en el lenguaje no puede significar reiteración de una terminología que, a fuerza de convertirse en común, apenas permite el alumbramiento de nuevas reflexiones. Claridad en el lenguaje significa precisión en las ideas que se abordan, rigurosidad a la hora de exponerlas, y sobre todo independencia y osadía suficientes como para crear nuestro propio universo reflexivo, y no una copia del que ya existe en la colectividad y que de ese modo, cualquiera creería inmutable, intocable por perfecto. Heráclito se ganó la reputación de ser un pensador oscuro, mas sus observaciones siguen esclareciendo algunas de nuestras ideas de última hora, y eso es lo que vale, aunque al mismo tiempo otros opten por un lenguaje digamos más transparente: en ambos casos hay provecho, en tanto lo que importa es la autenticidad del pensamiento que se expresa, su fecundidad.

Lo ideal sería una actitud ne quid nimis: en el justo medio. Confieso que a mí en lo particular me interesa cultivar (ya sé que a veces no con mucha suerte) el estilo diáfano $\mathrm{y}$, salvando la distancia que me separa de ese gran sabio que fue Jaime Balmes, he hecho mía las palabras que a principios del siglo xix escribió al redactar su Metafísica:

Evito el lenguaje embrollado de algunos filósofos modernos; pero adopto el que ha introducido la necesidad o el uso. He procurado expresar las ideas con la mayor claridad y precisión que me ha sido posible cuidando al propio tiempo de que las formas del estilo y de la dicción fuesen tales, que los jóvenes al salir de la escuela pudieran emplearlas en la discusión común; ¿de qué sirve el aprender cosas buenas si luego no se saben expresar?. La enseñanza no es para las pequeñas vanidades del recinto de la escuela, es para el bien del mundo. (Balmes 116)

No otro es mi modesto testimonio de que más que el post me interesa el past, entendiendo que es en ese pasado donde podemos encontrar los pilares más sólidos para nuestras peripecias intelectuales. Después de todo, ¿qué es un postcrítico sino un rastreador infatigable en la geografía de aquello soslayado temporalmente por la modernidad?; ¿qué es si no esa cosa pensante empeñada en vincular las obsesiones del ayer más remoto con las del hoy más candente, que al final, son las mismas?; ¿qué es una crítica imperfecta si no el testimonio de nuestra ansiedad de algún día saber algo más o menos perdurable? Sí, Andre Gide, el tiempo te sigue concediendo la razón: “Todo está dicho. Lo que como nadie atiende...”.

Mas cuando hablo de crítica imperfecta lo hago sin pensar en críticos o postcríticos. Tal como todavía la entiendo, la crítica imperfecta es aquella que de manera premeditada 
se aleja de los moldes adocenados y ya seguros con que una “conciencia común” (validada por el gusto autoritario que puede "avalar” Internet, los premios, los críticos o la Academia, por ejemplo) decide qué es bueno y qué es malo. La crítica imperfecta es una alternativa a la otra, y prefiere convertir a su “imperfección” (su singularidad) en razón de ser de un crecimiento intencional, por lo que vive más orgullosa de sus preguntas que de sus respuestas: para el crítico imperfecto lo primero es poner en claro de dónde le llega ese conocimiento a través del cual evalúa una determinada obra, pues por lo general la exégesis más tradicional sigue prefiriendo creer en lo irrevocable de aquellas lecciones que ya le transmitieron “ciertas autoridades intelectuales”, y es luego de esa petición de principio, que declama ante el espectador todo su discurso, toda su construcción de significados. Al faltar esta suspicacia radicalmente individual, al existir esta renuncia a llegar por mí mismo al origen del estímulo crítico, se adocenan los planteamientos y sobre todo las supuestas conclusiones, y en nombre de eso que conocemos por "sentido común" se establecen sistemas interpretativos a los cuales no les interesa la percepción natural del individuo, sino la fabricación de una armonía abstracta que en la realidad bien sabemos que nunca existe.

Si vivimos la época de la supuesta ilustración audiovisual, no se entiende que cada vez sean menos los espectadores que estén dispuestos a asumir una postura de sospecha ante aquello que a fuerza de tanta reiteración nos han hecho creer "perfecto y natural”; de allí la urgencia de una crítica que reintegre la autoestima del espectador, que lo invite a ejercer la suspicacia individual como otra manera de aspirar a un estadio existencial superior, que lo haga ver al crítico no como un ser sobrenatural dotado de conocimientos irrefutables o un dictador de patrones sagrados, sino como un verdadero provocador de su propia gestión intelectual. El espectador moderno no necesita hermeneutas empeñados en fijar el sentido único de un determinado filme, ni aristócratas del saber que descubren "la belleza” más allá de esta vida; en todo caso, el espectador moderno demanda de un enfoque holístico que tome en cuenta nuestra existencia como un todo, con sus virtudes y sus imperfecciones: se trata de contribuir a educar los sentidos de ese espectador cada vez más aturdido con la explosión de los mass-media y redescubrirle el placer de ver mejor u oír más.

La crítica imperfecta sabe que la belleza está en la vida, en los hechos que la componen, y no en un mundo idílico inventado por brillantes arquitectos del más allá y prometido como recompensa estética a quienes se sumen a su criterio sectario; la crítica imperfecta detesta el materialismo grosero, pero igual aborrece esa metafísica delirante que gusta de embriagarse con la interpretación y deja a un lado la percepción pura: el crítico tiene la obligación de meditar sobre los significados ocultos en la experiencia audiovisual más cotidiana, estimular en el espectador el culto a sus sentidos y la autoestima de su racionalidad práctica.

La crítica imperfecta plantea problemas, no soluciones, y algunas de sus preguntas más urgentes pudieran ser éstas: ¿debemos seguir planteando una crítica que no tome en cuenta las transformaciones que a diario acontecen en el universo productivo del audiovisual?; ¿cómo ejercer el criterio e influir en medio de un mundo que ha reemplazado lo presencial con lo "virtual”?; ¿cómo discutir sobre la calidad de esto o aquello que ya no es imprescindible apreciar en un espacio institucional, es decir, en una sala 
cinematográfica, en una cinemateca o en un cine club, sino del cual se puede conocer y hasta apreciar a través de los cada vez más prolíficos mass-media?; ¿cómo hacer la crítica de un objeto que ya no requiere de la percepción socializada?; ¿cómo llegar a un espectador cada vez más “informado” pero en igual medida menos “social”?; ¿cómo luchar contra la cada vez más creciente disneylización del pensamiento humano? En principio, no creo que quede otra alternativa que transmutar las viejas estrategias, desfasaje que ya en los tempranos años sesenta Julio García Espinosa intuía en la relación "nuevo cine cubano/ crítica”. Entonces se preguntaba y respondía: “¿Qué sucede en la actualidad? Que no pocos de nuestros críticos más esforzados han cambiado la intención y no la actitud, han cambiado la superficie y no el fondo, han desviado su atención de aquel sector de la clase media para centrarlo en el público mayoritario pero utilizando el mismo lenguaje y los mismos valores que destinaban a aquéllos. Sin contar que todavía pueda haber alguno que siga haciendo de la crítica un feudo particular" ("La crítica” 12).

No sé si hoy hay mejores condiciones que entonces para corregir el rumbo y reasumir con responsabilidad la que a la larga resulta la verdadera tarea del crítico, sintetizada de manera contundente por Susan Sontag en su célebre diatriba contra los interpretadores: "La función de la crítica debiera consistir en mostrar cómo es lo que es, incluso qué es lo que es, y no en mostrar qué significa”. Ignoro si las condiciones serán mejores, pero es preciso rebelarse contra esa dictadura crítica que piensa en las obras apenas como el pretexto que les hará lucir el lenguaje de unos pocos elegidos y desviar la atención de lo inexcusable: nuestra propia existencia. La misión principal del crítico imperfecto: reintregrar la confianza de los espectadores en sus propios sentidos, recordarle que el acto inicial de apreciar el arte es una acción personal, sensual e intransferible y que es a partir de la madurez de sus posiciones que puede alcanzarse una rigurosidad colectiva; nuestro gran lema: aquel mensaje de Shakespeare a un amigo, asegurándole que nunca nadie le haría una mayor alabanza que la de saber que él era solo él.

Pues, ¿de qué vale una crítica armónica, cumplidora hasta la saciedad de las lecturas institucionales, si sólo unos pocos se beneficiarán con ella?, ¿ya la vida llegó a su fin que un grupo de eruditos se autoproclaman dueños de las grandes verdades estéticas?: esta crítica perfecta y excluyente olvida que la proporción de puntos de vista siempre estará en correspondencia con el número de hombres que habitan la existencia, y que la verdad nunca pertenece a un grupo exclusivo, sino que se alimenta de las más variadas e insospechadas fuentes. En tal sentido, no necesitamos críticas eruditas, sino en todo caso, sabias: la erudición suele ser vanidad de feria, espejismo efímero que nunca alcanza a sugerir nuevos caminos ni a reconocer la esencia de los ya transitados; la sabiduría, sin embargo, es un esfuerzo plural, una búsqueda perenne de esa verdad que nos rebasa a todos, pero que empieza en cada uno de nosotros. La crítica, como el cine, como la vida, demanda de hombres sabios antes que incautos eruditos. 
Balmes, Jaime. Curso de filosofía elemental. París: Casa Editorial Garnier Hermanos, s.f. García Borrero, Juan Antonio. “Las estrategias de un provocador”. Festival de Huelva, 2001.

Por una crítica imperfecta. Buenos Aires, c. 2000.

García Espinosa, Julio. Una imagen recorre el mundo. La Habana, Cuba: Editorial Letras Cubanas, 1979.

Aventuras de Juan QuinQuin. Julio García Espinosa, dir. La Habana: ICAIC, 1976.

"Por un cine imperfecto". Hojas de cine. Testimonios y documentos del nuevo cine latinoamericano. Vol. III. México, D.F.: Dirección General de Publicaciones y Medios, Secretaría de Educación Pública/Fundación Mexicana de Cineastas, A.C./ Universidad Autónoma Metropolitana, 1988.

“La crítica y el público”. Revista Cine cubano 1/3 (noviembre 1960): 12-13.

Padrón Nodarse, Frank. “La eternidad y una pregunta: ¿la postcrítica?” (Inédito). Presentada en el Noveno Taller Nacional de la Crítica Cinematográfica en Camagüey, el 14 de marzo del 2001.

Ríos, Alejandro. "Veinte años sí son algo". La Gaceta de Cuba.

Varona, Enrique José. “Los aciertos de la crítica”. Violetas y ortigas. Madrid: EditorialAmérica, 1906. 